
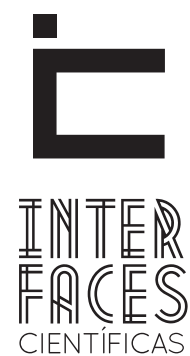

HUMANAS E SOCIAIS

\title{
REFLEXÕES SOBRE AS PRIMEIRAS REPERCUSSÕES TEÓRICAS E SOCIAIS DAS RELAÇ̃̃ES MEDIADAS PELA INTERNET ${ }^{1}$
}

\section{RESUMO}

As novas formas de intersubjetividade instauradas pela internet exercem grande fascínio e encontram-se no centro das discussões acerca das influências da internet. 0 presente artigo teórico discorre sobre diferentes visões de autores que analisam o impacto social da internet. 0 artigo tem como objetivo apresentar uma genealogia da rede, explicitando as vicissitudes históricas que subjazem o discurso da rede como promotora de transformação social.

\section{PALAVRAS-CHAVE}

Internet. Sociabilidade. Comunicação. Rede. 


\section{ABSTRACT}

The new forms of intersubjectivity brought by internet have had great fascination and are at the center of discussions about the influence of the internet. This theoretical paper discusses about different visions of authors who analyze the social impact of the Internet. The article also presents a genealogy of the network, explaining the historical events that underlie the discourse of the network as a promoter of social transformation.

\section{KEYWORDS}

Internet. Sociability. Communication. Network

\section{RESUMEN}

Las nuevas formas de interacciones subjetivas traídas por Internet, han tenido una gran fascinación y se encuentran en el centro de las discusiones de éste asunto específicamente. Este trabajo teórico, analiza diferentes puntos de vista de los autores que analizan el impacto social del Internet. El artículo tiene como objetivo, presentar una genealogía de la red, lo que

explica los acontecimientos históricos que subyacen en el discurso de la red como un promotor de la transformación social.

\section{PALABRAS CLAVE}

Internet. Sociabilidad. Comunicación. Red 


\section{INTRODUÇ̃̃̃o}

O surgimento de novas tecnologias oriundas da convergência da informática com as telecomunicações, nas últimas décadas do século XX, trouxe grandes mudanças que alcançam o campo econômico, político e das relações sociais. Novos comportamentos e maneiras de relacionar-se têm sido instaurados e mediados pelas novas tecnologias digitais neste início de século XXI.

0 advento da internet instaurou a possibilidade da comunicação à distância em tempo real, extrapolando as fronteiras de tempo e espaço. As inúmeras inovações tecnológicas advindas de uma informática cada vez mais avançada afetam diretamente o cotidiano urbano/ocidental contemporâneo - o que tem levado a alguns autores afirmarem que um novo mundo começou com a internet.

Este artigo, que faz parte de uma tese de doutorado, sobre as implicações políticas das relações de amizades mediadas pela internet, tem como objetivo elucidar as primeiras repercussões teóricas e sociais das relações mediadas pela internet, por meio de uma revisão da literatura sobre diferentes visões que analisam o impacto social da internet. 0 artigo apresenta ainda, uma genealogia da rede, explicitando as vicissitudes históricas que subjazem o discurso da rede como promotora de transformação social.

\section{SOBRE OS IMPACTOS DIANTE DAS INOVAÇOES TECNOLÓGICAS}

Wellman (2004), ao destacar a euforia diante das novidades tecnológicas, faz referência a John Perry Barlow, líder da Electric Frontier Foundation, que em 1995 afirmou: "com o desenvolvimento da Internet, e com o aumento da comunicação entre computadores ligados em rede, nós estamos no meio do maior evento de transformação tecnológica desde a captura do fogo [...]" (BARLOW, 1995, citado por WELLMAN, 2004, p.32. Tradução nossa).

A despeito dessa afirmação exagerada de Barlow, pois as inovações tecnológicas da era da grande indústria produziram transformações profundas no cotidiano do homem do pós-guerra, o qual também vivenciou uma época de crise e permaneceu igualmente atônito diante das novidades da modernidade, Wellman (2004) aponta que as análises iniciais do impacto da internet que a acreditavam como igualitária e difundida globalmente foram frequentemente utópicas e não levou em conta o fato de que diferenças de poder e status afetam tanto as interações on line quanto as off-line.

A hipótese de Musso (2003) é que a ideologia contemporânea de rede traz consigo as marcas de uma utopia social e do imaginário de rede próprios do pensamento construído no início do século XIX por Claude Henri de Saint-Simon. De acordo com Musso (2003), desde o final do século XIX, a narrativa mítica da transformação social pela rede foi reativada e revisitada no momento de cada inovação das técnicas reticuladas, da eletricidade à internet.

Em sua genealogia da rede, Musso (2003) demonstra que entre 1880 e 1910 se multiplicam as ficções e utopias tecnológicas relativas às redes elétricas. A apresentação da energia elétrica é vivida como uma revolução que vai transformar a vida cotidiana; a eletricidade vai substituir o vapor que dominou o século XIX, notadamente nas indústrias e nos transportes férreos. Ainda conforme Musso (2003) o discurso da utopia tecnológica é marcado por um lado, pela temática da revolução sociotécnica, operada pela ruptura das condições prévias da sociedade existente e a promessa de uma nova. Por outro lado, pela metáfora do cérebro ou sistema nervoso. "Por uma analogia de funcionamento lógico e uma similitude de arquitetura material, a rede 
técnica seria para a sociedade ou para o planeta o que o cérebro e o sistema nervoso são para o corpo humano, a saber, os órgãos de sua regulação". (MUSSO, 2003, p. 243. Tradução nossa).

Segundo Musso (2003) a vulgata saint-simoniana produzida pelos engenheiros politécnicos abriu caminho para a fetichismo da rede com as estradas de ferro e para a formulação de uma tecno-utopia da rede. 0 fetichismo da rede como símbolo de mudança social funciona à recorrência dos discursos apologéticos tomados no momento da emergência das redes elétricas ao final do século XIX, depois das telecomunicações e em fim da informática (MUSSO, 2003). "Esses discursos articulam sempre a nova rede à metáfora orgânica e à utopia técnico-política da transformação social: esta nova rede será 'viva' e 'revolucionária'. Tal teatralização parece necessária à promoção de cada inovação técnica reticular". (MUSSO, 2003, p.242. Tradução nossa).

Musso (2003) sugere que o discurso contemporâneo de rede é marcado por seis características da operação simbólica saint-simoniana sobre a ideia e a imagem de rede. A primeira delas, destacada por Musso (2003) como a mais potente e mais antiga, é qualificada como biotecnológica, já que se funda na analogia entre rede e o corpo, em particular entre o cérebro e a rede. $\mathrm{O}$ autor afirma que tal modelo do organismo-rede permite naturalizar a nova técnica, visto que a torna "calorosa", além de ajudar sua inserção social, apresentando-a como uma necessidade para renovar o corpo social.

A segunda marca da rede concerne ao fato de que sua lógica de funcionamento está inscrita no desenho de sua estrutura, de sua arquitetura, ou seja, ela indica que a rede responde a uma razão gráfica representada pelos laços (ou correspondências) estabelecidos entre os lugares (ou elementos) sobre um plano. A terceira marca saint-simoniana corresponde a transformação da sociedade pela rede. A rede é revolucionária por natureza, anuncia uma mudança na estrutura social existente e a promessa de uma mo- dernidade direcionada ao futuro; a nova rede levaria a democracia, a transparência e a igualdade. A quarta característica é a contribuição da rede à paz e à associação universal, visto que ela realiza uma cobertura artificial do planeta.

A quinta marca corresponde à passagem da crise ao desenvolvimento econômico. A rede traz a prosperidade, o progresso, novas atividades, a multiplicação de novos serviços, uma nova economia. A sexta tem caráter libertário. Em sua própria arquitetura a rede inscreve uma escolha de sociedade ou de política; a rede pode descentralizar e se tornar um meio de luta contra a concentração, até mesmo uma ferramenta de autogestão. “Pode-se ler e 'ver' uma política na arquitetura da rede. Ainda, a rede desloca a política e a inscreve nas escolhas técnicas" (MUSSO, 2003, p.248. Tradução nossa).

Segundo Musso (2003) são esses três níveis, das formas, dos fluxos e de uma regulação, que dão força à tecno- utopia da rede e que estruturam os discursos recorrentes que acompanham as inovações reticulares, desde o caminho de ferro até a internet.

A atenção não se deterá nas transformações instauradas pelos avanços tecnológicos da era da grande indústria, também, não se fará uma análise maniqueísta das tecnologias. Não obstante, diante das declarações entusiastas sobre a internet, é preciso pontuar que outras épocas de crise já foram vivenciadas a partir da irrupção de novidades tecnológicas. E que mais do que entusiasmo, as novas formas de relações implantadas pelos novos aparelhos tecnológicos requerem uma análise de suas implicações éticas e políticas, pois as tecnologias alteram a percepção, a sensibilidade, e os relacionamentos, uma vez que operam, antes, no registro da produção de subjetividade - tal como destaca Guattari (1993).

De acordo com Guattari (1993) pode-se falar de produção maquínica da subjetividade mesmo nas sociedades "pré-capitalistas" e "arcaicas" cujas for- 
mas de existência, também, foram modelizadas por diversos dispositivos maquínicos. As novas máquinas atreladas à convergência da informática com as telecomunicações incidem sobre os modos de produção de imagens, pensamentos, afetos, e enunciados.

O surgimento da internet é bastante recente e tem promovido mudanças de hábitos, novas representações de tempo e espaço, novos modos de conhecimento, novos estilos de relacionamentos sociais, ainda pouco estabilizados, seus efeitos em longo prazo ainda não foram analisados. Não obstante, nenhuma reflexão sobre a cultura contemporânea pode desconsiderar a enorme influência da informática que tem promovido a experimentação de novos vínculos e novas trocas simbólicas.

A revolução da tecnologia da informação está intrinsecamente relacionada com as especificidades da economia capitalista e com as vicissitudes do seu atual momento histórico. Castells (1999) aponta que a revolução tecnológica atual foi moldada pelas lógicas e interesses do capitalismo avançado, executando um papel essencial no processo de reestruturação do sistema capitalista a partir da década de 1980. Contudo, o próprio autor destaca que as manifestações desse desenvolvimento tecnológico não se limitaram aos interesses do capitalismo.

0 advento da internet e seu desenvolvimento nas últimas três décadas do século $X X$ foram consequências de um conjunto de forças que envolveram estratégia militar, cooperação científica, inovação tecnológica e concepção de contracultura. Segundo Castells (1999) a internet teve origem no trabalho da Agência de Projetos de Pesquisa Avançada (ARPA) do departamento de defesa dos Estados Unidos. No entanto, ainda que o surgimento da internet tenha sido proporcionado pelas pesquisas patrocinadas pelo departamento de defesa, Castells (1999) ressalta que somente num período posterior, a internet foi utilizada para fins militares, no mesmo período em que começou a ser difundida em redes de contracultura.
Wellman (2004), em seu texto sobre as eras de estudos da internet, demonstra três fases bem marcadas e diferenciadas num período de 10 anos. Primeiramente o autor relata uma época denominada de pré-história que corresponde ao período de 19901994, representando o período pré-internet, marcada pelo surgimento da teleconferência e de pesquisas que buscavam novas aplicações do computador. De acordo com Wellman (2004) a primeira era de estudos da internet se deu entre 1994-2000, contexto no qual forças econômicas alimentavam a ideia de aplicações do computador que sustentassem redes sociais; foi a época de grande encantamento e crescimento da internet, onde se discutiam as questões da conectividade e transporte de dados.

A segunda era (2001-2005) corresponde ao período no qual interesses comerciais e acadêmicos apontam a necessidade de clientes sistemáticos da internet. Há um crescimento do uso da internet no cotidiano e começam a surgir pesquisas e bibliografia voltadas para a documentação desta proliferação de usos da rede bem como da quantidade de usuários. Estes estudos produziram muita informação sobre estatísticas do número de internautas, compararam diferenças demográficas e compreenderam quais coisas básicas as pessoas fazem na internet. No entanto, como destaca Wellman (2004), mesmo com o crescimento do uso do ciberespaço, a lacuna socioeconômica persiste na maioria dos países, pois as pessoas mais pobres não estão aumentando a sua taxa de uso tanto quanto os abastados. Ele relata que apesar da esperança de Barlow, a internet não tem trazido a utopia da comunicação globalmente difundida e da democracia. Por outro lado, o autor aponta que diferentemente das preocupações que surgiram com o fato de que alto nível de uso da internet atrairia as pessoas para longe das relações face a face, o que parece ocorrer é que quanto mais as pessoas usam a rede, mais elas se encontram com pessoas nas relações face a face, isto se dá, segundo Wellman (2004), porque a internet ajuda a arranjar encontros interpessoais e contribui para manter encontros em meio aos relacionamentos. 
A terceira era corresponde aos dias atuais e caracteriza-se pelo uso da rede para estabelecimento de relações sociais. Na segunda eram os pesquisadores que utilizavam métodos científicos para documentar a natureza da internet, agora os pesquisadores estão mais focados em projetos teórico-dirigidos voltados, por exemplo, em compreender os tipos de relacionamentos que a internet fomenta e como os empresários internacionais operam intercontinentalmente, tanto on line quanto off-line. 0 atual cenário de conectividade ubíqua, portabilidade e mobilidade wireless da internet está facilitando um movimento para longe das interações nos grupos familiares, convergindo para redes individualizadas.

Como destaca Wellman (2004) a internet está favorecendo que cada pessoa se torne uma comunicação entre pessoas, redes e instituições. Além disso, o autor informa que os atuais softwares de redes sociais facilitam as pessoas a fazerem novos vínculos, por meio dos "fabricantes de amizade" que colocam amigos de amigos em contato ou usam filtros colaborativos para pôr em contato pessoas com interesses similares - o que é relatado pelos alunos de Wellman (2004) como sendo efetivo e agradável, mas ao mesmo tempo gerador de exclusão. Grupos têm claramente se tornado redes dentro e fora da internet - conforme atenta Wellman (2004, p. 45), “a pessoa tem se tornado ela mesma o portal".

\section{POSICIONAMENTOS INICIAIS SOBRE AS RELAÇ̃ES TRAVADAS NA INTERNET: DA NEGATIVIDADEÀ CRENÇA NA REVOLUÇ̃̃O DEMOCRÁTICA VIA REDE}

Cada vez mais as relações sociais estão sendo mediadas pelas tecnologias da informática. Lévy (1993) aponta que a técnica, ao mediatizar as relações humanas, é intrinsecamente política. A informática, portanto, está profundamente implicada nos processos de subjetivação individuais e coletivos.
Não obstante, Nicolaci-da-Costa (2005) demonstra que essas novas formas de sociabilidade mediadas pela internet geram reações negativas radicais desde a sua difusão em meados da década de 1990. Segundo essa autora, diferentemente da recepção social amena dos celulares, pois a telefonia celular foi percebida como uma continuidade da telefonia fixa, a internet ainda gera comoção, uma vez que foi percebida como fator de rompimento das formas tradicionais de relacionamentos e de trabalho.

Castells (1999) relata que para uma equipe de psicólogos da Carnegie Mellon University, que analisou, entre 1995 e 1996, o efeito social e psicológico da internet em relação à sociabilidade e bem-estar psicológico, o uso intensivo da internet foi relacionado com o declínio de comunicação entre os familiares que residem em mesmo lar, com a diminuição da abrangência do círculo social, e com o aumento da depressão e isolamento.

Tamanho grau de crítica negativa faz com que Castells (1999) em sua análise da sociedade em rede, ao se referir à sociabilidade via internet, aponte que desde os seus primórdios ela esteve associada às crenças negativas de que seu uso levaria ao aumento de solidão e alienação, até mesmo à depressão.

Nicolaci-da-Costa (2005) indica que muitos intelectuais de diferentes países expressaram rejeição no que tange ao uso da internet para fins de sociabilidade, dentre eles, Sennett (1999), Bauman (2004). Aquela autora faz uma análise crítica das considerações de Bauman (2004) sobre a fragilidade das relações interpessoais contemporâneas, argumentando que as reações negativas desse autor à sociabilidade virtual são infundadas. A autora aponta que as relações virtuais não são definidas por Bauman (2004) levando-se em consideração suas características próprias e atuais, mas por uma oposição, indireta e confusa, aos relacionamentos "reais" ou face a face do período no qual as tecnologias digitais não existiam. 
Bauman (2004), ao atentar para as dificuldades de estabelecer vínculos duradouros nos tempos atuais, destaca uma nova modalidade discursiva diferente da linguagem dos relacionamentos - a linguagem da "conectividade". Segundo ele essa nova linguagem prefere falar em "redes", em vez de parceiros, e cada vez mais substitui termos como "relacionar-se" e "relacionamentos" em conexões, ou "conectar-se" e "ser conectado". Diferentemente dos "relacionamentos reais" essas "relações virtuais" são marcadas pela expansão da velocidade em que surgem e desaparecem, em volume cada vez maior, além da fluidez de entrada e saída que estas permitem, pois uma "rede" pressupõe as duas possibilidades: conectar e desconectar.

De acordo com Bauman (2004) essa facilidade da interrupção a qualquer momento, da falta de compromisso e do desengajamento fazem com que as relações tipo "virtuais" sejam cada vez mais praticadas corriqueiramente, o que tem levado a um crescente aniquilamento e vigoroso desuso das habilidades sociais próprias da condição não-virtual da relação face a face. As ferramentas de sociabilidade atrofiam-se expansivamente, o que leva Bauman (2004, p. 84) afirmar que "a solidão por trás da porta fechada de um quarto com um telefone celular à mão pode parecer uma condição menos arriscada e mais segura do que compartilhar o terreno doméstico comum".

Segundo Bauman (2004) a inédita fluidez e a transitoriedade dos vínculos sociais diluem as habilidades e o trabalho exigido no encontro traumático com o outro que afeta, além de solapar a confiança, fazendo com que a manutenção da parceria signifique um risco enorme. Todavia, conforme Bauman (2004), a frouxidão dos laços não reduz os riscos, apenas os distribuem de forma diferente, provocando ansiedades outras.

Para Nicolaci-da-Costa (2005) essas considerações de Bauman (2004) as quais compreendem os relacionamentos virtuais como "frágeis", "transitórios", "superficiais”, compõem uma visão profundamente negativa e desprovida de fundamentação empírica e traz impactos negativos na medida em que é adotada como modelo para todos outros tipos de relacionamentos contemporâneos.

Nicolaci-da-Costa (2005) destaca que a concepção negativa de Bauman (2004) dos relacionamentos virtuais como "frágeis", "frívolos" que diluem a solidariedade e tornam as pessoas descartáveis e solitárias, em oposição aos relacionamentos "reais" modernos como "sólidos", "autênticos" e "profundos”, também, traz graves efeitos, pois se trata de uma visão recente que não levou em consideração a literatura já disponível sobre os relacionamentos virtuais mediados por diferentes tecnologias. A autora destaca que a depreciação das relações virtuais torna-se ainda mais grave por ser defendida por um intelectual do porte de Bauman. Esta gravidade se potencializa no caso do Brasil, conforme aponta a autora, pois o pequeno volume de pesquisas sobre o uso das novas tecnologias faz com que a visão de um autor tão conhecido como Bauman possa ser supervalorizada e assumida como verdade incontestável.

A difusão da internet foi vivenciada com grande alvoroço pelo surgimento de possibilidades inimagináveis no contexto das telecomunicações via telefone. 0 advento da interconexão dos computadores em rede mundial tornou possível o acesso a qualquer tipo de informação e o fato inédito de poder estabelecer contato com qualquer usuário - possibilidade associada à ideia de estar conectado a uma rede.

A euforia com a internet se deu, portanto, diante da possibilidade de experimentação de algo completamente novo, que permitiu formas desterritorializadas de interação, onde pessoas geograficamente distantes ou próximas podem estabelecer contatos bi-pessoais, ou coletivos por meio da comunicação “muitos-muitos” (LÉVY, 2003).

Nicolaci-da-Costa (2005) ressalta que a irrupção desses ambientes de encontros coletivos foi o que de 
fato revolucionou os padrões vigentes da comunicação a distancia, possibilitando que contatos interpessoais sejam travados virtualmente, enquanto que na era do telefone as relações virtuais eram restringidas aos relacionamentos iniciados no mundo físico.

Nicolaci-da-Costa (2005) relata que diferentemente da desvalorização dos relacionamentos virtuais, alardeada no momento de difusão da internet por alguns autores e mais recentemente presente na posição de Bauman (2004), pesquisas atuais têm demonstrado os aspectos positivos dos relacionamentos virtuais, revelando inclusive, que estes tendem a complementar os relacionamentos reais e não a substituí-los.

Nicolaci-da-Costa (2005) ao descrever alguns desses resultados, destaca que Rheingold (1996) foi um dos primeiros a apontar que a nova capacidade de comunicação coletiva mediada pela internet possibilita a formação de amizades e laços comunitários entre estranhos. A autora também cita os estudos de Katz, Rice e Aspden (2000) os quais revelam que o uso da internet tem promovido um maior crescimento na participação cívica e no engajamento político de seus usuários.

Pesquisas têm apontado que as relações virtuais podem ser solidárias e intensas, configurando a formação de fortes laços de amizade e até mesmo de casamentos reais, constituindo um movimento de transformação dos relacionamentos virtuais duradouros em relacionamentos reais, conforme atenta Nicolaci-da-Costa $(1998,2005)$.

De fato, as transformações inauguradas pelas novas formas de interações coletivas na internet parecem ocorrer significativamente no âmbito da sociabilidade e afetividade, compondo novos modos de relacionar-se com a alteridade e de fazer amigos - 0 que configura o ciberespaço como essencialmente político. Lévy (2003) foi um dos primeiros a ressaltar a dimensão ética e política do ciberespaço, destacando que este possibilita a composição de um ambiente democrático de trocas de saberes e de formação de laços solidários.

Com sua visão otimista do ciberespaço Lévy (2003) aponta que as desterritorializantes relações via internet possibilitam trocas de conhecimentos e competências, alimentando uma sociabilidade de saber, fomentando o que ele conceitua de "inteligência coletiva" - fundamentada por uma dimensão ético-política de reconhecimento do outro em sua inteligência, de valorização do outro como alguém com quem posso aprender. Portanto, segundo Lévy (2003) esses contatos interativos favorecem a constituição de coletivos inteligentes, de um espaço de enunciação democrático de elaboração de questões e negociação em tempo real, configurando o ciberespaço como “ágoras virtuais".

Essa "ágora eletrônica" é destacada por Lévy (2003) como uma forma de maior participação do povo na vida da cidade, espaço onde se pode discutir problemas comuns e experimentar modos de organização e de regulação coletivos a partir da multiplicidade e variedade, permitindo grandes coletividades comunicarem-se entre si em tempo real.

Essa política molecular fundamentada na "inteligência coletiva", dessa forma, possibilita a renovação do laço social, pois esta emerge das interações e dos contratos, forja-se nos projetos comuns, nas circulações e encontros que pressupõem a ética da hospitalidade onde os sujeitos, segundo Lévy (2003), precisam abraçar os desafios análogos a uma sinfonia na qual é necessário seguir as regras da polidez, ouvindo os outros, não gritar ou encobrir a voz dos outros coralistas, cantar de modo diferenciado, calar-se ou cantar em uma só voz, ou seja, encontrar uma coexistência harmônica entre sua própria voz e a dos outros melhorando o efeito do conjunto.

A concepção da rede como 'inteligência coletiva', difundida por Lévy (2003), condensa em si as marcas saint-simonianas da tecno-utopia já que atualiza a 
associação entre rede e corpo, bem como se funda na crença da transformação social por meio de trocas interpessoais cooperativas e promotoras de uma nova democracia.

Musso (2003) afirma que a tecno-utopia do ciberespaço recicla o velho imaginário do reticular já que a ideia de "inteligência coletiva" representa a imagem de uma rede universal conectando todos os cérebros interligados em escala planetária constituindo uma espécie de "cérebro planetário". Musso (2003) demonstra que o aparente discurso inovador da revolução democrática via internet, enquanto ideologia da utopia reproduz "velhos futuros", na medida em que retoma uma antiga imagem do reticular, bem como o já conhecido fetichismo da rede que anunciou a eletricidade como garantia da liberdade, igualdade e fraternidade. A reticulação contemporânea do ciberespaço não cessa de anunciar o caráter revolucionário da internet, utilizando-se para isso do imaginário antigo do discurso reticular facilitando a projeção no futuro de uma sociedade em rede.

A internet se tornou o meio para pensar e realizar a transformação social. A concepção de uma sociedade em rede entrelaça discursos e imagens do reticular para compreender o tecido social contemporâneo, trazendo a promessa de uma reconstituição do laço social esgarçado, graças às próteses técnicas.

Lemos (2003 p. 18) aponta que o maior uso da internet é para busca efetiva de conexão social, "Assim, ver o outro e ser visto, trocar mensagens e entrar em fóruns de discussão é, de alguma forma, buscar o sentimento de re-ligação".

Marques (2003) ao se aproximar de Léyy (2003) destaca que é a possibilidade do uso direto da palavra que constitui a internet como esfera pública virtual, possibilitando que ativistas fundem suas reivindicações sem passar pelos meios de comunicação dominantes que com seus filtros editoriais e ideológicos deturpam e ocultam de acordo com sua conveniência.
No entanto, ainda que Marques (2003), também, destaque a Internet como ambiente interativo descentralizado, de superação de barreiras como o espaço, permitindo que as pessoas se situem mundialmente, participando, debatendo, interagindo e agindo fora do contexto geográfico - o que não acontecia em outras esferas públicas destacadas por pensadores como Hannah Arendt, este autor enfatiza que ainda há um longo caminho a percorrer até desvendar-se todo o potencial da comunicação mediada pelo computador. Segundo ele, não há dúvida de que a Internet é uma ferramenta importante para permitir a articulação entre organizações e pessoas, porém destaca que o simples acesso ao computador não evita em muitos casos uma atitude passiva do usuário e levanta um importante questionamento: 0 acesso ao equipamento resolveria todos os problemas de ordem política?

Antes, o próprio o acesso à internet é uma questão política que revela as discrepantes desigualdades entre os países desenvolvidos do hemisfério norte e os subdesenvolvidos do hemisfério sul, bem como as diferenças regionais e socioeconômicas do uso da rede em um mesmo país. Castells (1999) destaca a desigualdade espacial no acesso à internet como um dos paradoxos mais impressionantes da era da informação e relata a considerável discrepância regional na difusão da internet, ressaltando que ainda que o acesso e uso da internet estejam crescendo rapidamente nas principais metrópoles de todos os continentes, o restante do mundo ainda está atrasado em relação à América do Norte e aos países desenvolvidos.

O sociólogo francês Dominique Wolton (2003) ao retratar as desigualdades instauradas pela internet chama atenção para o risco de desenvolvimento de uma concepção menos democrática da informação fundamentada na especialização por nível de conhecimento e condição financeira. Pois como relata Wolton (2003), na web existe uma especialização do tipo de informação de acordo com o público, e, além disso, ainda que cada um possa acessá-la livremente, a seleção da informação se dá pelo nível socioeconômico-cultural. 
Sobre a concepção que sustenta os novos serviços da internet, Wolton (2003, p. 95) afirma que "trata-se menos de um esforço de democratização do que de uma especialização das informações em função dos diferentes meios solváveis, pois o pagamento pela informação será indissociável destes novos serviços".

Wolton (2003) atenta para os perigos da seleção pela condição financeira e da segmentação dos conteúdos em função dos meios sociais, que têm como consequência as desigualdades socioculturais na utilização dos quatros serviços oferecidos pela web: informação, lazer, serviços, conhecimento. 0 autor aponta que as diferenças são maiores em relação à informação-conhecimento, visto que a maneira de construir a informação e de apresentá-la, bem como os procedimentos para pesquisá-la não são universais, estão relacionados às representações culturais. Portanto, para Wolton (2003) um dos nefastos riscos da internet está na dominação sociocultural que se legitima no sistema de valores próprios da cultura Ocidental.

\section{CONSIDERACÕ̃ES FINAIS}

Wolton (2003) convoca a resistir à ideologia dominadora e tecnocrata presente na Internet. Para este autor, a tecnologia de comunicações não basta para transformar o modo de trocas entre as pessoas, precisamente porque o importante no sistema técnico são os projetos políticos e culturais que o acompanham. De acordo com Wolton (2003), a internet reforça as capacidades individuais de comunicação. Não obstante, o individualismo já é um dos valores do capitalismo mundial. Assim, não se trata de uma revolução cultural.

Diferentemente da positividade dos posicionamentos de Lévy (2003) que compreendem o ciberespaço como ambiente democrático que favorece trocas solidárias de informação e conhecimento, Wolton (2003) ressalta que as características de autonomia, domínio e velocidade, inerentes à in- ternet correspondem ao cerne do ideal individualista liberal. A performance pautada na autonomia e ausência de controle, na possibilidade de escrever, apagar, arquivar, corresponder-se e comunicar-se em tempo real, são atrativos sedutores na cultura contemporânea de valorização da liberdade individual, o que faz com que a web alimente nefastas ilusões de uma sociedade na qual os homens podem se emancipar individualmente.

A ligação social nasce do senso de mútua dependência. Wolton (2003) e Sennett (1999) chamam atenção para o fato de que os imperativos neoliberais ao valorizarem a autonomia têm produzido o sentimento de dependência como uma condição vergonhosa.

Sennett (1999) atenta que as estratégias neoliberais, que produzem o sentimento de vergonha da dependência, trazem nefastas consequências, como o aniquilamento dos laços de confiança e compromissos mútuos, ameaçando a realização de qualquer empreendimento coletivo.

Segundo Sennett (1999) no atual contexto neoliberal, o problema de confiança se apresenta de duas maneiras: o laço de confiança simplesmente está ausente, ou há uma desconfiança mais ativa dos outros. 0 autor aponta que não só as empresas, mas todas as estruturas sociais que não promovem positivamente a interdependência humana geram a "mais neutra e vazia falta de confiança".

Sennett (1999) atenta que no capitalismo moderno a questão "quem precisa de mim" sofre um grande desafio, pois o sistema irradia indiferença. A falta de confiança, a reengenharia das instituições em que as pessoas são tratadas como descartáveis, reduz o sentido de que se é necessário aos outros.

No atual sistema neoliberal, o problema do caráter - entendido como ligação com o mundo, está na ausência de narrativa partilhada de dificuldade, na ausência de um destino compartilhado. Nessas 
condições, o "nós” comunal representa um pronome perigoso, configurando uma comunidade que teme o confronto organizado com a desordem econômica. Entretanto, Sennett (1999) atenta que um sistema que não oferece aos seres humanos motivos de união uns com os outros não pode preservar sua legitimidade por muito tempo.

Sennett (1999) e Wolton (2003) chamam atenção para o fato de que a internet, antes de constituir-se como instrumento apropriado para compor movimentos de resistência, é um dispositivo que está a serviço dos imperativos neoliberais. Nada mais propício ao lucro das grandes corporações internacionais do que um mecanismo que disponibiliza a venda de qualquer produto por meio de um simples movimento de "clicar". A velocidade estonteante das transações comerciais sem limites geográficos favorece o veloz crescimento dos produtos de consumo disponíveis na internet. Já se vive um contexto nas grandes metrópoles onde não é mais necessário deslocar-se fisicamente de casa para comprar qualquer produto em tempo hábil. A web é um mecanismo que potencializa o livre fluxo do capital e possibilita a reprodução dos imperativos neoliberais de consumo, autonomia e liberdade individual.

O imperativo da velocidade da internet bem como a sua condição de onipresença apropriados por restritos interesses comerciais e para a reprodução do ideal neoliberal de autonomia que geram ilusões de que "o mundo está em nossas mãos” podem trazer terríveis implicações políticas. Além dos problemas implicados com a reprodução da ideia de que são desnecessários uns aos outros - como destacado por Sennett (1999) e Wolton (2003), o acesso a uma veloz rede em banda larga quase onipresente tem sido utilizado como mais um dispositivo de controle.

Autores como Rheingold (1996) e Senra (1993) apontam a nova rede de telecomunicações mundial como uma nova espécie de panóptico que exerce uma vigilância muito mais pontual, ilumi- nando apenas zonas de interesses em detrimento de outras que ficam na sombra - diferente do panóptico de Bentham cuja visibilidade era total. De acordo com Senra (1993) trata-se de uma iluminação intermitente que não se dirige mais ao espaço, mas a um alvo a ser operado dentro de um plano específico.

As atuais tecnologias que operam a vigilância eletrônica constituem um sistema de controle, inclusive da privacidade, muito mais sutil e complexo, viabilizado por um novo leque de aparatos muito mais eficazes e astuciosos: "em vez de escutas telefônicas, o arsenal constará de programas informáticos que cruzam códigos de barras, cartões de crédito, números de contribuinte e todas as pistas que vamos deixando na sociedade da informação" (RHEINGOLD, 1996, p.353).

As sofisticadas e onipresentes redes de informação cada vez mais cooptadas pelo mercado instauram um controle insidioso na medida em que operam a mercadorização da privacidade. Rheingold (1996), ao destacar que o mercado constitui a bola da vez dos atuais mecanismos panópticos, aponta que não somente a privacidade tem vindo a mercadorizar-se, mas o próprio ato de consumir pode gerar informações de alto valor - que se tornam um novo produto retroalimentando o fluxo avassalador do consumo.

Rheingold (1996) alerta que os novos dispositivos de controle, que operam por meio de máquinas registradoras e cartões de crédito, nas mãos de manipuladores totalitários podem compor formas cínicas de transmissão de informações sobre o que se compra quais lugares se frequenta, por meio de uma espécie de dossiê pessoal eletrônico que armazena informações sobre hábitos de compra. A era da convergência de todas as facetas do mercado para a internet instaura a nova insídia do consumo que permite antecipar desejos na forma de atributos compráveis por meio do perfil do consumidor. 
Não obstante, Wolton (2003) sustenta que em meio à globalização econômica que se impõe de forma imperativa e angustiante, não se deve deixar de preservar a ideia de que as novas tecnologias representam incontestavelmente um espaço de abertura e de emergência de uma nova cultura solidária e em rede. Segundo Wolton (2003) a internet como suporte de uma nova solidariedade mundial - questão que tem sido discutida por vários autores, representa uma esperança para que as novas gerações não sucumbam no niilismo e se engajem na construção de um mundo melhor, no qual a solidariedade constitua uma resposta de generosidade e humanidade à implacável ordem da globalização econômica.

\section{REFERÊNCIAS}

BAUMAN, Z. 0 Mal-Estar da Pós-Modernidade. Tradução de Mauro Gama e Cláudia Martinelli Gama; revisão técnica de Luís Carlos Fridman. Rio de Janeiro: Jorge Zahar, 1998.

BAUMAN, Z. Amor Líquido: sobre a fragilidade dos laços humanos. Tradução Carlos Alberto Medeiros. Rio de Janeiro: Jorge Zahar, 2004.

BAUMAN, Z. Vida Líquida. Tradução Carlos Alberto Medeiros. Rio de Janeiro: Jorge Zahar, 2007.

CASTELLS, M. A sociedade em rede. 9.ed. Tradução Roneide Venâncio Majer. São Paulo: Paz e Terra, 1999.

COSTA, R. da. A Cultura Digital. São Paulo: PublifoIha, 2002.

GUATTARI, F. Da Produção de Subjetividade. Em: Imagem-máquina: a era das tecnologias do virtual. André Parente (org); tradução de Rogério Luz et al. Rio de Janeiro: 34, 1993.
LEMOS, A. Cibercultura. Alguns pontos para compreender a nossa época. Em: Olhares sobre a cibercultura. André Lemos e Paulo Cunha (orgs). Porto Alegre: Sulina, 2003.

LÉVY, P. As tecnologias da inteligência. O Futuro do Pensamento na Era da Informática. Tradução Carlos Irineu da Costa. Rio de Janeiro: 34, 1993.

MARQUES, F.P.J.A .Da conservação pública em terrenos digitais: horizontes e provocações sobre a validade de uma esfera pública virtual. In: Olhares sobre a cibercultura. André Lemos e Paulo Cunha (orgs). Porto Alegre: Sulina, 2003.

MUSSO. P. Critique des Réseaux. Presses Universitaires de France, 2003.

NICOLACI-DACOSTA, A. M. Sociabilidade virtual: separando o joio do trigo. Psicologia e Sociedade. 2005.

RHEINGOLD, H. A Comunidade Virtual. Tradução Helder Aranha. Lisboa, Gradiva, 1996.

SENNETT, R. A corrosão do caráter. Conseqüências pessoais do trabalho na sociedade capitalista. 3.ed. Trad. de M. Santarrita, Rio de Janeiro: Record, 1999.

SENRA, S. Max Headroom: o último jornalista. Em: Imagem-máquina: a era das tecnologias do virtual. André Parente (org); tradução de Rogério Luz et alii. Rio de Janeiro: 34, 1993.

WELLMAN, B. Three ages of internet studies: ten, five and zero years ago. New Media e Society, v.6 (1): 123129, 2004.

WOLTON, D. Internet, e depois? Uma teoria crítica das novas mídias. Trad. Isabel Crossetti. Porto Alegre: Sulina, 2003. 
Recebido em: 20 de Março de 2014

Avaliado em: 2 de Abri de 2014

Aceito em: 2 de abril de 2014
2. Professora Adjunta do Departamento de Psicologia da Universidade Federal de Sergipe, Doutora em Psicologia Social pela Universidade de São Paulo. Rua Monsenhor Olívio Teixeira, 640, edf. Bela Sintra, apt 401, Jardins, 49026225, Aracaju, SE, Brasil. E-mail: liviagng@ig.com.br

3. Professor Livre Docente do Instituto de Psicologia da Universidade de São Paulo. E-mail: nesj@terra.com.br 